\title{
Pharmacogenetics of dipeptidyl peptidase 4 inhibitors in a Taiwanese population with type 2 diabetes
}

\author{
Wen-Ling Liao ${ }^{1,2, *}$, Wen-Jane Lee ${ }^{3, *}$, Ching-Chu Chen ${ }^{4,5, *}$, Chieh Hsiang Lu ${ }^{6,7,8, *}$, \\ Chien-Hsiun Chen ${ }^{5,9}$, Yi-Chun Chou ${ }^{9}$, I-Te Lee ${ }^{10,11,12}$, Wayne H-H Sheu ${ }^{10,12,13,14}$, \\ Jer-Yuarn Wu ${ }^{5,9}$, Chi-Fan Yang ${ }^{9}$, Chung-Hsing Wang ${ }^{15,16}$, Fuu-Jen Tsai, ${ }^{5,17,18}$ \\ ${ }^{1}$ Graduate Institute of Integrated Medicine, China Medical University, Taichung, Taiwan \\ ${ }^{2}$ Center for Personalized Medicine, China Medical University Hospital, Taichung, Taiwan \\ ${ }^{3}$ Department of Medical Research, Taichung Veterans General Hospital, Taichung, Taiwan \\ ${ }^{4}$ Division of Endocrinology and Metabolism, Department of Medicine, China Medical University Hospital, Taichung, Taiwan \\ ${ }^{5}$ School of Chinese Medicine, China Medical University, Taichung, Taiwan \\ ${ }^{6}$ Department of Internal Medicine, Ditmanson Medical Foundation, Chiayi Christian Hospital, Chiayi City, Taiwan \\ ${ }^{7}$ Department of Nursing, College of Nursing and Health Sciences, DAYEH University, Changhua, Taiwan \\ ${ }^{8}$ Department of Business management, College of Management, National Chung Cheng University, Chia-yi, Taiwan \\ ${ }^{9}$ National Center for Genome Medicine, Institute of Biomedical Sciences, Academia Sinica, Taipei, Taiwan \\ ${ }^{10}$ Division of Endocrinology and Metabolism, Department of Internal Medicine, Taichung Veterans Hospital, Taichung, Taiwan \\ ${ }^{11}$ School of Medicine, Chung Shan Medical University, Taichung, Taiwan \\ ${ }^{12}$ School of Medicine, National Yang-Ming University, Taipei, Taiwan \\ ${ }^{13}$ School of Medicine, National Defense Medical Center, Taipei, Taiwan \\ ${ }^{14}$ Institute of Medical Technology, National Chung-Hsing University, Taichung, Taiwan \\ ${ }^{15}$ Department of Genetics and Metabolism, Children's Hospital of China Medical University, Taichung, Taiwan \\ ${ }^{16}$ School of Medicine, China Medical University, Taichung, Taiwan \\ ${ }^{17}$ Department of Medical Genetics, China Medical University Hospital, Taichung, Taiwan \\ ${ }^{18}$ Department of Health and Nutrition Biotechnology, Asia University, Taichung, Taiwan \\ *These authors have contributed equally to this work \\ Correspondence to: Fuu-Jen Tsai, email: d0704@www.cmuh.org.tw \\ Keywords: DPP-4 inhibitors, pharmacogenetics, Taiwanese, type 2 diabetes \\ Received: January 29, $2016 \quad$ Accepted: January 03, $2017 \quad$ Published: February 01, 2017
}

\section{ABSTRACT}

Dipeptidyl peptidase-4 (DPP-4) inhibitors are oral anti-hyperglycemic drugs enabling effective glycemic control in type 2 diabetes (T2D). Despite DPP-4 inhibitors' advantages, the patients' therapeutic response varies. In this retrospective cohort study, 171 Taiwanese patients with T2D were classified as sensitive or resistant to treatment based on the mean change in HbA1c levels. Using an assumption-free genome-wide association study, 45 single nucleotide polymorphisms (SNPs) involved in the therapeutic response to DPP-4 inhibitors $\left(P<1 \times 10^{-4}\right)$ were identified at or near PRKD1, CNTN3, ASK, and LOC10537792. A SNP located within the fourth intron of PRKD1 (rs57803087) was strongly associated with DPP-4 inhibitor response $\left(P=3.2 \times 10^{-6}\right)$. This is the first pharmacogenomics study on DPP-4 inhibitor treatment for diabetes in a Taiwanese population. Our data suggest that genes associated with $\beta$-cell function and apoptosis are involved in the therapeutic effect of DPP-4 inhibitors, even in the presence of additional oral anti-diabetic drugs. Our findings provide information on how genetic variants influence drug response and may benefit the development of personalized medicine. 


\section{INTRODUCTION}

Type 2 diabetes (T2D), also known as non-insulindependent diabetes mellitus, is a common complex disease with an increasing prevalence worldwide. In 2000, more than 171 million adults were diagnosed with T2D globally, which is expected to rise by $4.4 \%$, affecting 366 million adults by 2030 [1].

The current treatment for T2D aims to control blood glucose levels and prevent diabetic complications. Nowadays, several anti-hyperglycemic drugs are available for T2D therapy, including metformin, sulfonylureas, thiazolidinediones (TZDs), alpha-glucosidase inhibitors, and insulin injections [2]. However, many patients with T2D experience initial success with anti-hyperglycemic drugs, only to become resistant to monotherapy over time, thus necessitating either an ancillary anti-diabetic agent or a transition to insulin in order to restore acceptable glycemic control. Approximately $40 \%$ of the individuals being treated for T2D fail to reach the desired glycosylated hemoglobin (HbAlc) target of $<7 \%$. In a study of longterm glycemic control in T2D, Kahn et al. [3] showed accumulative incidences of monotherapy failures at 5 years, including $15 \%$ failure with rosiglitazone (a TZD), $21 \%$ metformin (a biguanide), and $34 \%$ glyburide (a sulfonylurea). Thus, it is important to identify novel therapies that are more effective against T2D.

Dipeptidyl peptidase 4 (DPP-4) inhibitors are a class of oral hypoglycemic drugs approved by the FDA in 2006. Mechanistically, DPP-4 inhibitors increase incretin levels such as the levels of glucagon-like peptide-1 (GLP-1) and glucose-dependent insulinotropic polypeptides (GIP). GLP-1 and GIP are gut hormones secreted from L and $\mathrm{K}$ cells in the intestine in response to food intake $[4,5]$. GLP-1 and GIP augment glucose-induced insulin release from pancreatic $\beta$-cells, suppress glucagon secretion, and slow gastric emptying $[4,5]$. Both hormones are DPP-4 target proteins and are rapidly degraded and inactivated by proteolysis [6, 7]. Therefore, DPP-4 inhibitors, which can slow enzymatic cleavage that prevents the degradation of active incretins (GLP-1 and GIP), are used to enhance incretin-induced glycemic control. They have been proposed as potential therapeutic agents for T2D treatment.

DPP-4 inhibitors enable effective glycemic control with a low risk of hypoglycemia, neutral effects on body weight, and the convenience of once-daily oral dosing, which may improve patient adherence to therapy [8]. Several studies $[9,10]$ demonstrated that DPP-4 inhibitor treatment may be associated with a reduced incidence of cardiovascular (CV) events. Furthermore, DPP-4 inhibitors augment insulin secretion and increase $\beta$-cell mass by stimulating $\beta$-cell differentiation and proliferation by reducing oxidative and endoplasmic reticulum stress, inflammation, and apoptosis both in vitro and in preclinical models of T2D [11-15]. Recently, the DPP-4 inhibitors linagliptin [16] and saxagliptin [17] have been shown to improve glycemia and $\beta$-cell function in clinical trials. For these reasons, DPP-4 inhibitors are expected to improve treatment outcomes in patients with $\mathrm{T} 2 \mathrm{D}$.

A number of factors contribute to inter-individual differences in anti-diabetic drug responses, including age, sex, disease, drug and food interactions, co-morbidity, and genetic factors. A recent meta-analysis revealed that DPP-4 inhibitors decrease glycated hemoglobin (HbA1c) levels more markedly in Asians than in non-Asians [18], and the clinical factors underlying DPP-4 inhibitor resistance have been examined more intensely in Asian subjects [19-22]. Thus, genetic variations among different ethnic groups may alter the metabolism and therapeutic response of DPP-4 inhibitors, as previously demonstrated by pharmacogenomic and pharmacogenetic studies [23, 24]. Accordingly, the genetic effects of several genes such as DPP4 [25, 26], GLP1R [27, 28], and TCF7L2 [29] on the therapeutic response of DPP-4 inhibitors in patients with T2D have been investigated in clinical trial and casecontrol studies with a candidate gene approach. In the present report, we used an assumption-free genome-wide association study (GWAS) to identify the potential genes involved in the therapeutic response to DPP-4 inhibitors among patients with T2D in a Taiwanese population. While this is the first pharmacogenomic study of DPP-4 inhibitor treatment for diabetes in a Taiwanese population, the findings could provide some information on how genetic variants influence drug response and may benefit the development of personalized medicine.

\section{RESULTS}

The study population consisted of 171 diabetic patients in stage I undergoing DPP-4 inhibitor therapy for GWAS. Four different DPP-4 inhibitors were prescribed, including sitagliptin, saxagliptin, vildagliptin, and linagliptin. The number of patients in each drug category was $114(66.7 \%), 22(12.9 \%), 23(13.5 \%)$, and $12(7 \%)$, respectively. Among them, 169 patients (98.9\%) used DPP-4 inhibitors as a second treatment. Additionally, $29.8 \%$ and $64.3 \%$ of the patients were taking one or two oral anti-diabetic drugs (OADs), respectively, at the beginning of the study, and metformin and sulfonylurea were the two most common OADs used in the population. Detailed demographic and clinical characteristics of these patients are presented in Table 1. After DPP-4 inhibitor therapy, the patients exhibited significant differences in $\triangle \mathrm{HbA} 1 \mathrm{c}$ values, both with and without baseline $\mathrm{HbA} 1 \mathrm{c}$ stratification ( $p<0.001$; data not shown). Further analysis revealed that the mean value of $\Delta \mathrm{HbA} 1 \mathrm{c}$ was significantly different among patients with different baseline $\mathrm{HbA} 1 \mathrm{c}$ levels because patients with higher baselines $(>8 \%)$ displayed greater treatment responses $(p<0.001)$ (Table $2)$. Therefore, patients were classified as either sensitive or resistant based on their responses to DPP-4 inhibitor 
Table 1: Demographics of the study population in GWAS stage (stage I) for DPP-4 inhibitor pharmacogenomics study

\begin{tabular}{|c|c|c|c|c|}
\hline & Total $(N=171)$ & $\operatorname{Men}(\mathrm{N}=\mathbf{8 0})$ & Women $(\mathrm{N}=91)$ & $\mathbf{P}\left(\zeta^{\lambda} \mathbf{v s}+\right)$ \\
\hline \multicolumn{5}{|l|}{ Age (years) } \\
\hline$\leqq 60$ years (median) & $89(52.0 \%)$ & $43(53.8 \%)$ & $46(50.5 \%)$ & \\
\hline$>60$ years & $82(48.0 \%)$ & $37(46.3 \%)$ & $45(49.5 \%)$ & 0.679 \\
\hline \multicolumn{5}{|l|}{ BMI $\left(\mathrm{kg} / \mathrm{m}^{2}\right)$} \\
\hline$<24$ & $49(28.7 \%)$ & $23(34.8 \%)$ & $26(33.3 \%)$ & \\
\hline 24-27 & $41(24.0 \%)$ & $20(30.3 \%)$ & $21(26.9 \%)$ & \\
\hline$>27$ & $54(31.6 \%)$ & $23(34.8 \%)$ & $31(39.7 \%)$ & 0.820 \\
\hline Missing & $27(15.8 \%)$ & & & \\
\hline \multicolumn{5}{|l|}{ eGFR } \\
\hline$\geqq 60$ (median) & $116(67.8 \%)$ & $50(75.8 \%)$ & $66(89.2 \%)$ & \\
\hline$<60$ & $24(14.0 \%)$ & $16(24.2 \%)$ & $8(10.8 \%)$ & 0.035 \\
\hline Missing & $31(18.1 \%)$ & & & \\
\hline \multicolumn{5}{|l|}{ Baseline HbA1c (\%) } \\
\hline $7-<8 \%$ & $68(39.8 \%)$ & $35(43.8 \%)$ & $33(36.3 \%)$ & \\
\hline $8-<9 \%$ & $55(32.2 \%)$ & $25(31.3 \%)$ & $30(33.0 \%)$ & \\
\hline$\geqq 9 \%$ & $48(28.1 \%)$ & $20(25.0 \%)$ & $28(30.8 \%)$ & 0.564 \\
\hline Changed HbA1c (\%) & $-0.95 \pm 1.07$ & $-0.98 \pm 1.32$ & $-0.92 \pm 0.80$ & 0.716 \\
\hline DM duration (years) & $9.8 \pm 6.5$ & $9.32 \pm 5.77$ & $10.23 \pm 7.07$ & 0.361 \\
\hline FPG (mg/dL) & $176.77 \pm 47.53$ & $171.38 \pm 47.27$ & $181.43 \pm 47.53$ & 0.172 \\
\hline \multicolumn{5}{|l|}{ BP (mmHg) } \\
\hline Systolic BP & $133.69 \pm 15.61$ & $135.32 \pm 16.48$ & $132.18 \pm 14.79$ & 0.213 \\
\hline Diastolic BP & $80.34 \pm 8.97$ & $80.73 \pm 9.01$ & $79.97 \pm 8.98$ & 0.604 \\
\hline \multicolumn{5}{|l|}{ ОНА } \\
\hline 1 OHA & $2(1.2 \%)$ & $2(2.5 \%)$ & $0(0 \%)$ & \\
\hline 2 OHA & $51(29.8 \%)$ & $26(32.5 \%)$ & $25(27.5 \%)$ & \\
\hline 3 OHA & $110(64.3 \%)$ & $49(61.3 \%)$ & $61(67.0 \%)$ & \\
\hline 4 ОНА & $8(4.7 \%)$ & $3(3.8 \%)$ & $5(5.5 \%)$ & 0.446 \\
\hline
\end{tabular}

Values are presented as N (\%) or mean \pm SD; Abbreviation: BMI: body mass index; eGFR: estimated glomerular filtration rate; HbA1c: hemoglobin A1c; DMD: diabetes mellitus duration; FPG: fasting plasma glucose; BP: blood pressure; OHA: oral hypoglycemic agents. $\mathrm{P}$ value for two sample independent $\mathrm{t}$ test or ANOVA test

treatment (detailed information regarding the classification is provided in the Materials and Methods section). No significant association was observed between the response to DPP-4 inhibitor therapy and patient's sex, age, body mass index (BMI), disease duration, self-reported disease history (hypertension and cardiovascular disease), or lipid profile (cholesterol, triglycerides, high-density lipoprotein, and low-density lipoprotein) at enrollment (Table 3; all $p>$ $0.05)$. However, the treatment-sensitive patients tended to have higher a BMI $(>27)$ than their resistant counterparts (44.8\% vs. $31.2 \% ; p=0.052$ ) (Table 3$)$.
In stage I, a preliminary GWAS, performed in 83 sensitive and 88 resistant patients, identified 45 singlenucleotide polymorphisms (SNPs) associated with the DPP-4 inhibitor treatment response $\left(p<10^{-4}\right)$. A SNP located within the fourth intron of the protein kinase D1 gene (PRKD1; rs57803087) on chromosome 14 showed the strongest association with the DPP-4 inhibitor response $\left(p\right.$-value for the trend test $\left.=3.2 \times 10^{-6}\right)$ (Table 4). Two other SNPs, rs 10511037 and rs62266510, located on chromosome 3 were also associated with the treatment response and are approximately $5-\mathrm{kb}$ upstream of the 
Table 2: The HbA1c difference from baseline to 3 months after enrollment

\begin{tabular}{|c|c|c|c|}
\hline & $\mathbf{N}(\%)$ & $\begin{array}{c}\text { Changed HbA1c } \\
\text { Mean (SD) }\end{array}$ & P-value \\
\hline \multicolumn{4}{|l|}{ Sex } \\
\hline Male & $80(46.8 \%)$ & $-0.984(1.32)$ & 0.716 \\
\hline Female & $91(53.2 \%)$ & $-0.922(0.80)$ & \\
\hline \multicolumn{4}{|l|}{ Age } \\
\hline$\leqq 60$ & $89(52.0 \%)$ & $-0.988(0.96)$ & 0.641 \\
\hline$>60$ & $82(48.0 \%)$ & $-0.911(1.18)$ & \\
\hline \multicolumn{4}{|l|}{ eGFR } \\
\hline $50+$ & $128(74.9 \%)$ & $-0.907(0.82)$ & \\
\hline$<\mathbf{5 0}$ & $12(7.0 \%)$ & $-0.458(1.36)$ & 0.092 \\
\hline \multicolumn{4}{|l|}{ BMI } \\
\hline$<\mathbf{2 4}$ & $49(28.7 \%)$ & $-1.137(0.88)$ & \\
\hline $24-27$ & $41(24.0 \%)$ & $-0.866(1.37)$ & \\
\hline$>27$ & $54(31.6 \%)$ & $-0.813(0.81)$ & 0.243 \\
\hline \multicolumn{4}{|c|}{ DM duration } \\
\hline$\leqq 8$ & $86(50.3 \%)$ & $-0.998(0.98)$ & 0.567 \\
\hline$>8$ & $85(49.7 \%)$ & $-0.904(1.16)$ & \\
\hline \multicolumn{4}{|c|}{ Baseline HbA1c (\%) } \\
\hline $7-<8 \%$ & $68(39.8 \%)$ & $-0.465(0.52)$ & $<0.001$ \\
\hline $8-<9 \%$ & $55(32.2 \%)$ & $-0.918(0.76)$ & \\
\hline $9 \%+$ & $48(28.1 \%)$ & $-1.677(1.49)$ & \\
\hline
\end{tabular}

Abbreviation: BMI: body mass index; eGFR: estimated glomerular filtration rate; HbA1c: hemoglobin A1c; DM: diabetes mellitus; FPG: fasting plasma glucose; BP: blood pressure; OHA: oral hypoglycemic agents. P value for two sample independent $t$ test or ANOVA test

contactin 3 gene (CNTN3). Chromosome 6 contained two pairs of significant SNPs, rs7755097/rs9376211 and rs4946688/rs1948999, located in the intron region of the gene encoding apoptosis signal-regulating kinase $1(A S K 1)$ and within an uncharacterized gene, LOC105377923, respectively. After adjusting for BMI as a potential confounding factor, rs57803087 on chromosome 14 continued to be the most predictive of the DPP-4 treatment response, with the other SNPs also maintaining their statistical significance.

Subsequently, we replicated the six most significant SNPs from stage I in an additional 39 sensitive responders and 39 resistant responders. None of the SNPs showed a significant association with the DPP-4 inhibitor response. After the GWAS (stage I) and replication (stage II) results were combined, rs57803087, located within PRKD1, remained significantly associated with the DPP-4 inhibitor response (Table 4).

\section{DISCUSSION}

To our knowledge, this is the first pharmacogenomic study of DPP-4 inhibitor treatment for T2D in a Taiwanese population. In the present study, DPP-4 inhibitors served as an add-on therapy. More than $98 \%$ of the subjects used more than one OAD instead of DPP-4 inhibitors alone, and the average $\mathrm{HbA} 1 \mathrm{c}$ level was reduced by $0.95 \%$, which is comparable with the data from a previous report [9]. Several factors can influence the therapeutic response to DPP-4 inhibitors as a primary or ancillary treatment [19, 30]. Baseline $\mathrm{HbAlc}$ values and shorter disease durations are important predictors of the efficacy of OADs, including DPP-4 inhibitors [8]. In our retrospective cohort study, subjects with higher baseline HbA1c values showed a better therapeutic response to DPP-4 inhibitor treatment. However, no significant association with disease duration was observed.

DPP-4 inhibitors prevent the degradation of incretins, GLP-1 and GIP, in response to glucosedependent insulin secretion. Previous studies showed that polymorphism in DPP4 [25, 26] and GLP1R [27, 28], which are directly involved in the mechanism of action of DPP-4 inhibitors, was associated with the glycemic response to DPP-4 inhibitor treatment. Appropriate regulation of insulin secretion may also be related to DPP4 inhibitor efficacy. Our data indicate that genes associated 
Table 3: The baseline characters for sensitive groups and resistant groups

\begin{tabular}{|c|c|c|c|}
\hline & $\begin{array}{c}\text { Resistant Responders } \\
(\mathrm{N}=\mathbf{8 8})\end{array}$ & $\begin{array}{c}\text { Sensitive Responders } \\
(\mathbf{N}=\mathbf{8 3})\end{array}$ & $P$ value \\
\hline \multicolumn{4}{|l|}{ Sex } \\
\hline Male & $44(50 \%)$ & $36(43.4 \%)$ & \\
\hline Female & $44(50 \%)$ & $47(56.6 \%)$ & 0.385 \\
\hline \multicolumn{4}{|l|}{ Age } \\
\hline$\leqq 60$ & $51(58 \%)$ & $38(45.8 \%)$ & \\
\hline$>60$ & $37(42 \%)$ & $45(54.2 \%)$ & 0.111 \\
\hline \multicolumn{4}{|l|}{ BMI } \\
\hline$<24$ & $33(42.9 \%)$ & $16(23.9 \%)$ & \\
\hline 24-27 & $20(26.0 \%)$ & $21(31.3 \%)$ & \\
\hline$>\mathbf{2 7}$ & $24(31.2 \%)$ & $30(44.8 \%)$ & 0.052 \\
\hline \multicolumn{4}{|l|}{ eGFR } \\
\hline$\geqq \mathbf{5 0}$ & $66(91.7 \%)$ & $62(91.2 \%)$ & \\
\hline$<\mathbf{5 0}$ & $6(8.3)$ & $6(8.8 \%)$ & 0.918 \\
\hline \multicolumn{4}{|l|}{ DM duration } \\
\hline$\leqq 8$ & $50(56.8 \%)$ & $36(43.4 \%)$ & \\
\hline$>8$ & $38(43.2 \%)$ & $47(56.6 \%)$ & 0.079 \\
\hline \multicolumn{4}{|c|}{ Baseline HbA1c } \\
\hline $7-<8 \%$ & $35(39.8 \%)$ & $33(39.8 \%)$ & \\
\hline $8-<9 \%$ & $31(35.2 \%)$ & $24(28.9 \%)$ & \\
\hline $9 \%+$ & $22(25 \%)$ & $26(31.3 \%)$ & 0.566 \\
\hline \multicolumn{4}{|c|}{ Hypertension* } \\
\hline yes & $33(42.9 \%)$ & $35(47.3 \%)$ & 0.584 \\
\hline no & $44(57.1 \%)$ & $39(52.7 \%)$ & \\
\hline \multicolumn{4}{|c|}{ Cardiovascular disease* } \\
\hline yes & $4(8.3 \%)$ & $7(16.3 \%)$ & 0.246 \\
\hline no & $44(91.7 \%)$ & $36(83.7 \%)$ & \\
\hline Cholesterol & $169.44(29.51)$ & $172.38(29.47)$ & 0.534 \\
\hline Triglyceride & $149.06(104.43)$ & $166.75(144.39)$ & 0.384 \\
\hline HDL & $49.25(12.78)$ & $47.30(12.82)$ & 0.344 \\
\hline LDL & $99.25(28.07)$ & $99.65(29.93)$ & 0.933 \\
\hline
\end{tabular}

Values are presented as N (\%); Abbreviation: BMI: body mass index; eGFR: estimated glomerular filtration rate; HbA1c: hemoglobin A1c; DM: diabetes mellitus; HDL: high density lipoprotein; LDL: low density lipoprotein

*self-reported disease history P value for chi-square test.

with $\beta$-cell function and apoptosis may be involved in the therapeutic effect of DPP-4 inhibitors, even when additional OADs are used. First, rs9376211 is located withinthe ASK1 intron region on chromosome 6. Previous studies have shown that $A S K 1$ variants are associated with skeletal muscle ASK1 expression, in vivo insulin resistance, and T2D in Pima Indians [31]. ASK1 encodes the ASK1 protein, a member of the large mitogen-activated protein kinase kinase kinase (MAP3K) family that activates downstream MAPKs, c-Jun N-terminal kinase
(JNK) and p38 MAPK, and is essential for the cellular response to various stressors. As such, ASK1 signaling can elicit cell death, differentiation, inflammation, and survival $[32,33]$. In pancreatic $\beta$-cells, ASK1 is involved in the oxidative stress-induced thioredoxin-interacting protein (TXNIP)-dependent apoptosis cascade [32, 34]. Moreover, recent studies have demonstrated that the TXNIP signaling pathway is involved in inhibition of $\beta$-cell apoptosis by GIP $[35,36]$. Collectively, our data suggest that the increase in GIP concentration mediated 
Table 4: Summary of the SNPs associated with the effects of DPP-4 inhibitors in Type 2 diabetes in the GWAS stage and replication stage

\begin{tabular}{|c|c|c|c|c|c|c|c|c|c|c|}
\hline \multirow[b]{2}{*}{ dbSNP ID } & \multirow[b]{2}{*}{ Chr. } & \multirow[b]{2}{*}{ Nearest Gene } & \multicolumn{2}{|c|}{ GWAS } & \multicolumn{2}{|c|}{ Replication } & \multicolumn{4}{|c|}{ Overall } \\
\hline & & & $\begin{array}{c}\text { Resistant } \\
\text { Responders } \\
(\mathbf{n}=\mathbf{8 8})\end{array}$ & $\begin{array}{c}\text { Sensitive } \\
\text { Responders } \\
(\mathbf{n}=\mathbf{8 3})\end{array}$ & $\begin{array}{c}\text { Resistant } \\
\text { Responders } \\
(\mathbf{n}=39)\end{array}$ & $\begin{array}{c}\text { Sensitive } \\
\text { Responders } \\
(\mathbf{n}=39)\end{array}$ & $\begin{array}{l}\text { Resistant } \\
\text { Responders } \\
\quad(n=127)\end{array}$ & $\begin{array}{c}\text { Sensitive } \\
\text { Responders } \\
(\mathbf{n}=122)\end{array}$ & P value & Power \\
\hline rs10511037 & 3 & CNTN3 & $12.5 \%$ & $31.5 \%$ & $26.9 \%$ & $28.2 \%$ & $16.9 \%$ & $30.5 \%$ & $1.14 \mathrm{E}-06$ & $70.6 \%$ \\
\hline rs62266510 & 3 & CNTN3 & $15.9 \%$ & $33.9 \%$ & $32.1 \%$ & $34.6 \%$ & $20.9 \%$ & $34.1 \%$ & 2.94E-07 & $63.3 \%$ \\
\hline rs4946688 & 6 & LOC105377923 & $54.5 \%$ & $30.9 \%$ & $46.2 \%$ & $38.5 \%$ & $52.0 \%$ & $33.3 \%$ & $3.69 \mathrm{E}-16$ & $82.3 \%$ \\
\hline rs1948999 & 6 & LOC105377923 & $54.5 \%$ & $31.3 \%$ & $44.9 \%$ & $37.1 \%$ & $51.6 \%$ & $33.2 \%$ & $7.89 \mathrm{E}-16$ & $81.1 \%$ \\
\hline rs7755097 & 6 & ASK1 & $12.5 \%$ & $30.1 \%$ & $17.9 \%$ & $21.8 \%$ & $14.2 \%$ & $27.5 \%$ & $3.49 \mathrm{E}-06$ & $71.1 \%$ \\
\hline rs9376211 & 6 & ASK1 & $19.8 \%$ & $40.7 \%$ & - & - & - & - & - & - \\
\hline rs57803087 & 14 & PRKD1 & $17.0 \%$ & $38.6 \%$ & $19.2 \%$ & $26.9 \%$ & $17.7 \%$ & $34.8 \%$ & $2.51 \mathrm{E}-08$ & $86.5 \%$ \\
\hline
\end{tabular}

Abbreviation: dbSNP ID: SNP database identification; Chr: chromosome; GWAS

*Risk allele is the allele with higher frequency

by DPP-4 inhibitors may inhibit pancreatic $\beta$-cell death. Thus, patients harboring ASK1 variants, in whom GIPmediated cell protection is compromised, may be more resistant to this form of therapy.

A second SNP (rs57803087) was located in the intron region of the PRKD1 gene on chromosome 14. PRKD1 is a serine/threonine kinase that controls a variety of cellular functions, including membrane receptor signaling, Golgi transport, mitochondrial oxidative stress responses, gene transcription, cell morphology, motility, and adhesion [37]. Studies have demonstrated that agonists of G-proteincoupled receptor 40 (GPR40) and free fatty acid (FFA) receptor 1 (FFAR1) are induced by $\beta$-cell insulin secretion [38]. Additionally, PRKD1 activation contributes to the GPR40-mediated insulin secretion from $\beta$-cells [39]. FFAinduced GPR40 activation results in the generation of diacyl glycerol via the phospholipase C-mediated hydrolysis of membrane phospholipids, PRKD1 activation, cortical actin depolymerization, and potentiation of a second phase of glucose-stimulated insulin secretion [39]. Moreover, Kong et al. [40] have reported that the M3 muscarinic receptor promotes the insulin release via receptor phosphorylation/ arrestin-dependent PRKD1 activation. Importantly, both of these PRKD1 activation mechanisms potentiate insulin secretion.

There are several limitations to this study. First, we recognize that this study had low statistical power, owing to its limited sample size. Based on the sample size (127 resistant responders vs. 122 sensitive responders after combining the subjects from the stage I GWAS and stage II replication) and the difference in the allele frequency for the revealed SNPs (range: from $13.2 \%$ to $18.7 \%$ ), the power was $63.3 \%$ to $86.5 \%$ (Table 4 ). The results did not reach statistical significance after a Bonferroni correction, and false positive results may exist. Very little is known about the contribution of patient genetics to DPP-4 inhibitor responses. Therefore, analyses with larger sample sizes could potentially identify additional genetic variants to enable better predictions for personalized or stratified medicine. Second, metformin is known to increase GLP1 secretion by intestinal L-cells. Thus, the combination of metformin and DPP-4 inhibitor treatment may exert a stronger effect on $\beta$-cell function $[41,42]$. In the present study, $>98.8 \%$ of patients received other drug therapies in addition to DPP-4 inhibitors. For this reason, the therapeutic effect of single-agent DPP-4 inhibitors could not be determined. Third, the insulin secretory capacity decreases according to the duration of T2D [43] and could thus be another predictor of the DPP-4 inhibitor efficacy $[8,19,30]$. Accordingly, clinical trials have shown that the DPP-4 inhibitors linagliptin [16] and saxagliptin [17] better preserved $\beta$-cell function in recently diagnosed $(<24$ months) T2D patients. Similarly, the Saxagliptin Assessment of Vascular Outcomes Recorded in Patients with Diabetes Mellitus (SAVOR-TIMI 53) trial showed that saxagliptin-mediated preservation of $\beta$-cell function was better in patients with higher homeostatic model assessment 2 (HOMA2) scores prior to DPP-4 inhibitor treatment [17]. However, the baseline $\beta$-cell function was not measured in the present study. Thus, we cannot exclude the effect of variations in baseline $\beta$-cell function on the DPP-4 therapeutic response. Fourth, we were 
unable to exclude the possibility of drug interactions, which would need to be further investigated. For example, exposure to saxagliptin and its primary metabolite may be significantly modified when saxagliptin is co-administered with strong specific inhibitors (ketoconazole or diltiazem) or inducers (rifampicin) of the cytochrome P450 3A4/5 isoform [44]. Moreover, some lipid-lowering drugs such as statins could increase the HbA1c value. Unfortunately, the information on lipid-lowering drugs taken by the recruited patients simultaneously with DPP-4 drugs was not available. However, no significant differences in the hypertension history, cardiovascular disease history, or lipid profiles (cholesterol, triglycerides, low-density lipoprotein, and high-density lipoprotein) were observed between the responders and non-responders at enrollment; therefore, the potential for selection bias was minimal.

In conclusion, the current study utilized a GWASbased approach to examine the pharmacogenetics of DPP4 inhibitor treatment for T2D in a Taiwanese population. Our data indicate that genes associated with $\beta$-cell function and apoptosis may be involved in the therapeutic effect of DPP-4 inhibitors, even when additional OADs are used. However, further studies are required to confirm the association of the genes identified in this study with the therapeutic effect of DPP-4 inhibitors using a larger, more ethnically diverse patient population.

\section{MATERIALS AND METHODS}

\section{Study population identification}

This was a retrospective cohort study using data generated from a systematic chart review of diabetic patients from our previous study population $[45,46]$, treated with a consistent dosage of DPP-4 inhibitors for $>60$ days. Endocrinologists performed the chart review. Cotreatment with other OADs was permitted if dosing was maintained for 3 months before and after DPP-4 inhibitor treatment. However, no incretin analog was allowed together with the DPP-4 inhibitors. Subjects with type 1 diabetes or undergoing insulin therapy were excluded from the analyses. Because DPP-4 inhibitors are primarily excreted in the urine and could be subject to renal function-associated effects, subjects with estimated glomerular filtration rates (eGFRs) of less than $30 \mathrm{~mL} / \mathrm{min}$ per $1.73 \mathrm{~m}^{2}$ were excluded from the study. Additionally, patients with eGFRs between 30 and $50 \mathrm{~mL} / \mathrm{min}$ per 1.73 $\mathrm{m}^{2}$, taking $\leq 50 \mathrm{mg}$ of sitagliptin/vildagliptin or $\leq 2.5 \mathrm{mg}$ of saxagliptin/linagliptin, were also excluded. The study was approved by the Institutional Review Board of the China Medical University Hospital, and informed consent was obtained from all participants.

The patients were first stratified according to their baseline HbAlc values $(\leq 6.99 \%, 7-7.99 \%, 8-8.99 \%$, and $\geq 9 \%$ ) into four groups. The subjects were then classified as either sensitive or resistant to DPP-4 inhibitor treatment based on their treatment response change, determined by $\triangle \mathrm{HbA} 1$ (the difference in HbA1c values before and after treatment). In each group, subjects with the $\Delta \mathrm{HbA} 1$ values higher or lower than the mean $\Delta \mathrm{HbA} 1$ value for the group were defined as sensitive or resistant, respectively. In this two-stage study, we first genotyped 83 sensitive responders and 88 resistant responders via an exploratory genome-wide scan (stage I, total 171 subjects). In the replication stage, we genotyped six selected SNPs in an additional 39 sensitive responders and 39 resistant responders (stage II, total 78 subjects).

\section{Genotyping and statistical analysis}

Blood glucose and HbAlc levels were recorded before and $>60$ days after a DPP-4 inhibitor treatment course. Genomic DNA from blood samples was genotyped with an Affymetrix CHB chip using standard quality control procedures. SNPs with the following conditions were excluded from the analysis: (1) individuals or SNPs with a call rate of $<95 \%$; (2) $p \leq 0.0001$ for the Hardy-Weinberg test for control; (3) SNPs with a minor allele frequency of $<$ 0.01 ; (4) samples with first-degree cryptic relationships; and (5) samples that were potentially $9 \%$ contaminated. In total, 618,882 SNPs were included in the GWAS.

Various clinical variables were compared between groups using $\chi^{2}$ tests or two independent $t$-tests. The threshold $p$-value was set at $8.0 \times 10^{-8}$ after a Bonferroni correction for SNP numbers $(n=618,882)$. All statistical analyses were conducted using the SAS statistical software, version 9.1 (SAS Institute, Inc., Cary, NC, USA). $p<0.05$ (two-sided) was considered significant.

\section{ACKNOWLEDGMENTS}

We thank the National Center for Genome Medicine of the National Core Facility Program for Biotechnology, Ministry of Science and Technology, for the technical/ bioinformatics support.

\section{CONFLICTS OF INTEREST}

The authors declare no competing interest.

\section{FUNDING}

This work was supported in part by research grants from Biosignature project, Academia Sinica, Taiwan and China Medical University (CMU103-N-06).

\section{REFERENCES}

1. Wild S, Roglic G, Green A, Sicree R, King H. Global prevalence of diabetes: estimates for the year 2000 and projections for 2030. Diabetes Care. 2004; 27:1047-53. 
2. Morral N. Novel targets and therapeutic strategies for type 2 diabetes. Trends Endocrinol Metab. 2003; 14:169-75.

3. Kahn SE, Haffner SM, Heise MA, Herman WH, Holman RR, Jones NP, Kravitz BG, Lachin JM, O’Neill MC, Zinman B, Viberti G, and ADOPT Study Group. Glycemic durability of rosiglitazone, metformin, or glyburide monotherapy. N Engl J Med. 2006; 355:2427-43.

4. Kim W, Egan JM. The role of incretins in glucose homeostasis and diabetes treatment. Pharmacol Rev. 2008; 60:470-512.

5. Yamagishi S, Matsui T. Pleiotropic effects of glucagonlike peptide-1 (GLP-1)-based therapies on vascular complications in diabetes. Curr Pharm Des. 2011; 17:4379-85.

6. Cordero OJ, Salgado FJ, Nogueira M. On the origin of serum CD26 and its altered concentration in cancer patients. Cancer Immunol Immunother. 2009; 58:1723-47.

7. Yazbeck R, Howarth GS, Abbott CA. Dipeptidyl peptidase inhibitors, an emerging drug class for inflammatory disease? Trends Pharmacol Sci. 2009; 30:600-07.

8. Oh TJ, Jung HS, Bae JH, Kim YG, Park KS, Cho YM, Park KS, Kim SY. Clinical characteristics of the responders to dipeptidyl peptidase-4 inhibitors in Korean subjects with type 2 diabetes. J Korean Med Sci. 2013; 28:881-87.

9. Wu D, Li L, Liu C. Efficacy and safety of dipeptidyl peptidase-4 inhibitors and metformin as initial combination therapy and as monotherapy in patients with type 2 diabetes mellitus: a meta-analysis. Diabetes Obes Metab. 2014; 16:30-37.

10. Patil HR, Al Badarin FJ, Al Shami HA, Bhatti SK, Lavie CJ, Bell DS, O'Keefe JH. Meta-analysis of effect of dipeptidyl peptidase-4 inhibitors on cardiovascular risk in type 2 diabetes mellitus. Am J Cardiol. 2012; 110:826-33.

11. Vilsbøll T, Holst JJ, Knop FK. The spectrum of antidiabetic actions of GLP-1 in patients with diabetes. Best Pract Res Clin Endocrinol Metab. 2009; 23:453-62.

12. Campbell JE, Drucker DJ. Pharmacology, physiology, and mechanisms of incretin hormone action. Cell Metab. 2013; 17:819-37.

13. Drucker DJ, Nauck MA. The incretin system: glucagonlike peptide-1 receptor agonists and dipeptidyl peptidase-4 inhibitors in type 2 diabetes. Lancet. 2006; 368:1696-705.

14. Omar BA, Vikman J, Winzell MS, Voss U, Ekblad E, Foley JE, Ahrén B. Enhanced beta cell function and antiinflammatory effect after chronic treatment with the dipeptidyl peptidase-4 inhibitor vildagliptin in an advancedaged diet-induced obesity mouse model. Diabetologia. 2013; 56:1752-60.

15. Lee YS, Jun HS. Anti-diabetic actions of glucagon-like peptide-1 on pancreatic beta-cells. Metabolism. 2014; 63:9-19.

16. Heise T, Larbig M, Patel S, Seck T, Hehnke U, Woerle HJ, Dugi K. The dipeptidyl peptidase-4 inhibitor linagliptin lowers postprandial glucose and improves measures of $\beta$-cell function in type 2 diabetes. Diabetes Obes Metab. 2014; 16:1036-39.

17. Leibowitz G, Cahn A, Bhatt DL, Hirshberg B, Mosenzon O, Wei C, Jermendy G, Sheu WH, Sendon JL, Im K, Braunwald E, Scirica BM, Raz I. Impact of treatment with saxagliptin on glycaemic stability and $\beta$-cell function in the SAVOR-TIMI 53 study. Diabetes Obes Metab. 2015; 17:487-94.

18. Kim YG, Hahn S, Oh TJ, Kwak SH, Park KS, Cho YM. Differences in the glucose-lowering efficacy of dipeptidyl peptidase-4 inhibitors between Asians and non-Asians: a systematic review and meta-analysis. Diabetologia. 2013; 56:696-708.

19. Kim SA, Shim WH, Lee EH, Lee YM, Beom SH, Kim ES, Yoo JS, Nam JS, Cho MH, Park JS, Ahn CW, Kim KR. Predictive clinical parameters for the therapeutic efficacy of sitagliptin in korean type 2 diabetes mellitus. Diabetes Metab J. 2011; 35:159-65.

20. Tajiri Y, Tsuruta M, Ohki T, Kato T, Sasaki Y, Tanaka K, Kono S, Tojikubo M, Yamada K. Long-term efficacy of sitagliptin for the treatment of type 2 diabetic patients in Japan. Endocr J. 2012; 59:197-204.

21. Harashima SI, Ogura M, Tanaka D, Fukushima T, Wang Y, Koizumi T, Aono M, Murata Y, Seike M, Inagaki N. Sitagliptin add-on to low dosage sulphonylureas: efficacy and safety of combination therapy on glycaemic control and insulin secretion capacity in type 2 diabetes. Int J Clin Pract. 2012; 66:465-76.

22. Chung HS, Suh S, Kim MY, Kim SK, Kim HK, Lee JI, Hur KY, Kim JH, Min YK, Lee MS, Kim KW, Kim SW, Chung $\mathrm{JH}$, et al. Predictive factors of durability to sitagliptin: slower reduction of glycated hemoglobin, older age and higher baseline glycated hemoglobin. J Diabetes Investig. 2014; 5:51-59.

23. Liao WL, Tsai FJ. Personalized medicine in Type 2 Diabetes. Biomedicine (Taipei). 2014; 4:8.

24. Maruthur NM, Gribble MO, Bennett WL, Bolen S, Wilson LM, Balakrishnan P, Sahu A, Bass E, Kao WH, Clark JM. The pharmacogenetics of type 2 diabetes: a systematic review. Diabetes Care. 2014; 37:876-86.

25. Kwon O, Choe EY, Choi Y, Kim HM, Wang HJ, Lee H, Kim HC, Kang ES. Discovery of DiPeptidyl Peptidase-4 Gene Variants and the Associations with Efficacy of Vildagliptin in Patients with Type 2 Diabetes - A Pilot Study. J Diabetes Metab. 2013; S13:6.

26. Ahmed RH, Huri HZ, Al-Hamodi Z, Salem SD, Al-Absi B, Muniandy S. Association of DPP4 Gene Polymorphisms with Type 2 Diabetes Mellitus in Malaysian Subjects. PLoS One. 2016; 11:e0154369.

27. Han E, Park HS, Kwon O, Choe EY, Wang HJ, Lee YH, Lee SH, Kim CH, Kim LK, Kwak SH, Park KS, Kim $\mathrm{CS}$, Kang ES. A genetic variant in GLP1R is associated with response to DPP-4 inhibitors in patients with type 2 diabetes. Medicine (Baltimore). 2016; 95:e5155. 
28. Javorský M, Gotthardová I, Klimčáková L, Kvapil M, Židzik J, Schroner Z, Doubravová P, Gala I, Dravecká I, Tkáč I. A missense variant in GLP1R gene is associated with the glycaemic response to treatment with gliptins. Diabetes Obes Metab. 2016; 18:941-44.

29. Zimdahl H, Ittrich C, Graefe-Mody U, Boehm BO, Mark M, Woerle HJ, Dugi KA. Influence of TCF7L2 gene variants on the therapeutic response to the dipeptidylpeptidase- 4 inhibitor linagliptin. Diabetologia. 2014; 57:1869-75.

30. Lim S, An JH, Shin H, Khang AR, Lee Y, Ahn HY, Yoon JW, Kang SM, Choi SH, Cho YM, Park KS, Jang HC. Factors predicting therapeutic efficacy of combination treatment with sitagliptin and metformin in type 2 diabetic patients: the COSMETIC study. Clin Endocrinol (Oxf). 2012; 77:215-23.

31. Bian L, Hanson RL, Ossowski V, Wiedrich K, Mason CC, Traurig M, Muller YL, Kobes S, Knowler WC, Baier LJ, Bogardus C. Variants in ASK1 are associated with skeletal muscle ASK1 expression, in vivo insulin resistance, and type 2 diabetes in Pima Indians. Diabetes. 2010; 59:1276-82.

32. Hayakawa R, Hayakawa T, Takeda K, Ichijo H. Therapeutic targets in the ASK1-dependent stress signaling pathways. Proc Jpn Acad, Ser B, Phys Biol Sci. 2012; 88:434-53.

33. Ichijo $H$, Nishida E, Irie $K$, ten Dijke $P$, Saitoh $M$, Moriguchi T, Takagi M, Matsumoto K, Miyazono K, Gotoh Y. Induction of apoptosis by ASK1, a mammalian MAPKKK that activates SAPK/JNK and p38 signaling pathways. Science. 1997; 275:90-94.

34. Chen J, Saxena G, Mungrue IN, Lusis AJ, Shalev A. Thioredoxin-interacting protein: a critical link between glucose toxicity and beta-cell apoptosis. Diabetes. 2008; 57:938-44.

35. McIntosh CH, Widenmaier S, Kim SJ. Glucose-dependent insulinotropic polypeptide signaling in pancreatic $\beta$-cells and adipocytes. J Diabetes Investig. 2012; 3:96-106.

36. Widenmaier SB, Ao Z, Kim SJ, Warnock G, McIntosh CH. Suppression of p38 MAPK and JNK via Akt-mediated inhibition of apoptosis signal-regulating kinase 1 constitutes a core component of the beta-cell pro-survival effects of glucose-dependent insulinotropic polypeptide. J Biol Chem. 2009; 284:30372-82.

37. Eiseler T, Döppler H, Yan IK, Kitatani K, Mizuno K, Storz P. Protein kinase D1 regulates cofilin-mediated F-actin reorganization and cell motility through slingshot. Nat Cell Biol. 2009; 11:545-56.

38. Itoh Y, Kawamata Y, Harada M, Kobayashi M, Fujii R, Fukusumi S, Ogi K, Hosoya M, Tanaka Y, Uejima H, Tanaka H, Maruyama M, Satoh R, et al. Free fatty acids regulate insulin secretion from pancreatic beta cells through GPR40. Nature. 2003; 422:173-76.

39. Ferdaoussi M, Bergeron V, Zarrouki B, Kolic J, Cantley J, Fielitz J, Olson EN, Prentki M, Biden T, MacDonald PE, Poitout V. G protein-coupled receptor (GPR)40-dependent potentiation of insulin secretion in mouse islets is mediated by protein kinase D1. Diabetologia. 2012; 55:2682-92.

40. Kong KC, Butcher AJ, McWilliams P, Jones D, Wess J, Hamdan FF, Werry T, Rosethorne EM, Charlton SJ, Munson SE, Cragg HA, Smart AD, Tobin AB. M3-muscarinic receptor promotes insulin release via receptor phosphorylation/arrestin-dependent activation of protein kinase D1. Proc Natl Acad Sci USA. 2010; 107:21181-86.

41. Mulherin AJ, Oh AH, Kim H, Grieco A, Lauffer LM, Brubaker PL. Mechanisms underlying metformin-induced secretion of glucagon-like peptide-1 from the intestinal L cell. Endocrinology. 2011; 152:4610-19.

42. Migoya EM, Bergeron R, Miller JL, Snyder RN, Tanen M, Hilliard D, Weiss B, Larson P, Gutierrez M, Jiang G, Liu F, Pryor KA, Yao J, et al. Dipeptidyl peptidase-4 inhibitors administered in combination with metformin result in an additive increase in the plasma concentration of active GLP-1. Clin Pharmacol Ther. 2010; 88:801-08.

43. U.K. Prospective Diabetes Study Group. U.K. prospective diabetes study 16 . Overview of 6 years' therapy of type II diabetes: a progressive disease. Diabetes. 1995; 44:1249-58.

44. Scheen AJ. Dipeptidylpeptidase-4 inhibitors (gliptins): focus on drug-drug interactions. Clin Pharmacokinet. 2010; 49:573-88.

45. Tsai FJ, Yang CF, Chen CC, Chuang LM, Lu CH, Chang CT, Wang TY, Chen RH, Shiu CF, Liu YM, Chang CC, Chen $\mathrm{P}$, Chen $\mathrm{CH}$, et al. A genome-wide association study identifies susceptibility variants for type 2 diabetes in Han Chinese. PLoS Genet. 2010; 6:e1000847.

46. Liao WL, Tsai FJ. Personalized medicine in Type 2 Diabetes. Biomedicine (Taipei). 2014; 4:8. 